\title{
Lower urinary tract dysfunction in cerebral palsy
}

\author{
C J D Reid, Matgorzata Borzyskowski
}

\begin{abstract}
The clinical features and management of 27 children with cerebral palsy referred with symptoms of lower urinary tract dysfunction were reviewed. The mean age at referral was 9.9 years. Daytime urinary incontinence was the commonest presenting symptom. Videourodynamic studies were abnormal in 23 patients $(85 \%)$. Only two children had evidence of upper renal tract damage. Treatment was determined by urodynamic findings, and led to improvement in symptoms in all patients for whom there was follow up information.

Urinary incontinence may be improved or cured in children with cerebral palsy. These children would therefore benefit from early referral for assessment and treatment.

(Arch Dis Child 1993; 68: 739-742)
\end{abstract}

It is generally perceived that urinary incontinence is commoner in children with cerebral palsy than in normal children. Several factors may predispose to incontinence, including impairment of cognitive and communication skills, and reduced mobility. A review of the literature reveals few published data on this problem, though it appears that children with cerebral palsy have a significant incidence of lower urinary tract symptoms. ${ }^{1}$ We have reviewed our own findings.

\section{Patients and methods}

We reviewed the management of 27 patients with cerebral palsy referred with lower urinary tract symptoms to a paediatric neurourology clinic over the past 10 years. These symptoms included urinary incontinence, urgency, and frequency. The reasons for referral included failure of incontinence to respond to usual methods of management, concern that the symptoms may be due to a neuropathic bladder, and evidence from investigations done before referral of bladder dysfunction. It is important to note that none of the children was referred with nocturnal enuresis alone. Our initial assessment included a full history with particular attention to practical difficulties with toiletting, and any history of urinary tract infection (UTI). If UTIs had occurred and had not already been investigated, then appropriate investigations, including renal ultrasound and DMSA scan, were undertaken. Videourodynamic studies were performed in all 27 patients.

This procedure consists of a filling and voiding cystometrogram combined with a micturating cystourethrogram, which are recorded simultaneously onto videotape, and then viewed side by side using a split screen display so that events occurring in the bladder and urethra can be correlated with pressure changes. This is a well established technique for investigating bladder and urethral function, as described by Whiteside ${ }^{2}$ and Bates et al. ${ }^{3}$ The children are not sedated as this may affect detrusor function. However, lignocaine jelly is used in boys to anaesthetise the urethra before catheterisation. A rectal pressure line is the only additional feature for the child when compared with a micturating cystourethrogram. The bladder was filled at a rate of $2 \%$ of the expected bladder capacity of a child of the same age per minute. The expected bladder capacity is calculated as (age in years $\times 25$ ) $+25 \mathrm{ml} .{ }^{4}$ Filling was discontinued when the child indicated bladder fullness or when significant leakage occurred. During this filling phase the children were supine. Voiding was performed while standing upright, except in two children who were unable to stand. Methods and definitions conform to the standards recommended by the International Continence Society. ${ }^{5}$ Videourodynamic studies have been performed on children at this hospital for the past 14 years, and the reproducibility of the technique has been well established. ${ }^{+}$

\section{Results}

Of the 27 patients who underwent videourodynamic studies, there were 18 girls and nine boys. The mean age at referral was 9.9 years, with a range of 3-20 years. Nearly half of the patients referred for assessment were over 11 years old. Twelve children had normal intellectual development and attended mainstream school, while 15 children had intellectual delay of varying severity. The classification of their cerebral palsy is shown in table 1 .

\section{SYMPTOMS (TABLE 2)}

Incontinence was the commonest presenting symptom, occurring in 20 of the 27 patients (74\%). Seventeen children had always wet themselves, while two developed incontinence aged 9 years and one at 11 years. The same number of children wet themselves during the day only and both night and day. Frequency was a symptom in 15 patients $(56 \%)$, and $10(37 \%)$ complained of urgency. Three patients had difficulty initiating voiding, and a further two presented with urinary retention. Only four children were considered unable to communicate their need to go to the toilet.

\section{VIDEOURODYNAMIC FINDINGS (TABLE 3)}

These were abnormal in 23 patients $(85 \%)$. Hyper-reflexic detrusor contractions (involuntary contractions during bladder filling in the presence of a known neurological disorder) with reduced bladder capacity was the commonest finding, in 20 of these 23 patients (87\%). Five of
C J D Reid

Matgorzata Borzyskowski

Drrespo

Accepted 10 February 1993 
Table 1 Classification of cerebral palsy $(n=27)$

\begin{tabular}{lr}
\hline Pyramidal: & \\
Spastic monoplegia & 1 \\
Spastic hemiplegia & 5 \\
Spastic diplegia & 10 \\
Spastic quadriplegia & 7 \\
Pyramidal+extrapyramidal (mixed): & 1 \\
Diplegia & 3 \\
Quadriplegia & \\
\hline
\end{tabular}

Table 2 Presenting urological symptoms

\begin{tabular}{llrr}
\hline & Boys & Girls & Total \\
\hline Incontinence & 5 & 15 & 20 \\
Day and night & 0 & 10 & 10 \\
Day only & 5 & 5 & 10 \\
Night only & 0 & 0 & 0 \\
Stress & 0 & 2 & 2 \\
Urgency & 5 & 5 & 10 \\
Frequency & 4 & 11 & 15 \\
Giggle incontinence & 1 & 1 & 2 \\
Hesitancy/difficulty initiating voiding & 1 & 2 & 3 \\
Urinary retention & 2 & 0 & 2 \\
Urinary tract infection & 0 & 2 & 2
\end{tabular}

these patients also had detrusor-sphincter dyssynergia (DSD), a detrusor contraction concurrent with involuntary contraction of the external urethral sphincter. Presenting symptoms did not distinguish this group from those patients without DSD.

\section{URINARY TRACT INFECTION}

At referral, UTI had occurred in 13 children. Four children had a history of a single previous UTI and seven had a history of two or more. In two children, aged 0.8 years and 3.8 years, UTI was the initial presenting problem. Videourodynamic studies revealed vesicoureteric reflux (VUR) in only one patient, who also had hyperreflexia and DSD. Two patients were shown to have bilateral reflux nephropathy with impaired renal function. Micturating cystourethrography before referral had demonstrated bilateral VUR in both cases, though reflux was no longer evident when videourodynamic studies were performed.

\section{MANAGEMENT}

This was determined by the urodynamic findings. Table 4 summarises the treatment given and response seen in the 22 patients for whom we have full follow up information. The mean duration of follow up is 4.58 years (range 0.21 $15 \cdot 2$ years). Prophylactic antibiotics were prescribed for those patients with recurrent UTI
Table 4 Treatment and response in 22 patients

\begin{tabular}{llll}
\hline Treatment & Total & Improved & No change \\
\hline Anticholinergics & 9 & 9 & 0 \\
Adrenergics & 1 & 1 & 0 \\
CIC & 1 & 1 & 0 \\
CIC+anticholinergics & 4 & 3 & 1 \\
Surgery & 2 & 2 & 0 \\
No treatment in five: & & \\
Normal videourodynamic findings $(\mathrm{n}=3)$ & \\
Spontaneous improvement $(\mathrm{n}=1)$ & & \\
Aged only 3 years $(\mathrm{n}=1)$ &
\end{tabular}

$\mathrm{CIC}=$ clean intermittent catheterisation.

and those with VUR. Premicturition and postmicturition ultrasound scanning of the renal tract was routinely performed to assess the adequacy of bladder emptying in those patients commenced on anticholinergic drugs or clean intermittent catheterisation. Response to treatment was assessed by interview with parents and child, and in addition through reports from the child's school in some cases. Repeat videourodynamic studies were not performed in children who improved, and were undertaken in only one patient, who showed an initial good response to oxybutynin but then became incontinent again after 11 months. The initial study had revealed a small capacity hyper-reflexic bladder, with some narrowing in the mid-portion of the urethra. Repeat videourodynamic studies showed hyperreflexia only, and reintroduction of oxybutynin was effective.

All nine patients treated with anticholinergic drugs alone (oxybutynin or propantheline) for hyper-reflexia showed improvement in their symptoms; five became completely dry after an average of 15 months and no longer required treatment. Four patients required clean intermittent catheterisation for incomplete bladder emptying in addition to anticholinergics. One of these patients remained incontinent despite this management, and clean intermittent catheterisation became technically difficult. She now has an indwelling catheter. One patient who presented with urinary retention remains dry with undilated upper renal tracts on clean intermittent catheterisation alone. Of the five patients requiring clean intermittent catheterisation, three showed hyper-reflexia and DSD, one had hyper-reflexia and incomplete emptying but no DSD, and the patient who presented with urinary retention was unable to void during videourodynamic studies.

Adrenergic treatment (ephedrine) was successful in treating the incontinence of one patient who wet herself when she coughed,

Table 3 Videourodynamic findings and symptoms

\begin{tabular}{|c|c|c|c|c|c|c|c|}
\hline & Total $^{\star}$ & Hesitancy & Retention & Incontinence & Urgency & Frequency & $\begin{array}{l}\text { Stress } \\
\text { incontinence }\end{array}$ \\
\hline \multirow{6}{*}{$\begin{array}{l}\text { Hyper-reflexia + reduced capacity } \\
\text { Hyper-reflexia + DSD + reduced } \\
\text { capacity } \\
\text { Hyper-reflexia + reduced capacity } \\
\text { +open bladder neck } \\
\text { Open bladder neck + stress } \\
\text { incontinence } \\
\text { Hyper-reflexia, unable to void } \\
\text { Reduced compliance + poor } \\
\text { emptying }\end{array}$} & 9 & & & 8 & 5 & 6 & \\
\hline & 5 & & 1 & 4 & 2 & 2 & \\
\hline & 6 & 2 & & 4 & 3 & 4 & 1 \\
\hline & 1 & & & & & 1 & 1 \\
\hline & 1 & 1 & 1 & & 1 & & \\
\hline & 1 & & & 1 & & 1 & \\
\hline
\end{tabular}

$\star$ Findings were normal in four children. 
strained, or laughed: videourodynamic studies revealed an open bladder neck, compatible with bladder neck weakness.

Two patients underwent surgery. One presented with urinary retention and upper tract dilatation as a neonate after delivery at 28 weeks' gestation, Streptococcus faecalis meningitis, and bilateral intraventricular haemorrhage. A vesicostomy was created. Videourodynamic studies revealed a hyper-reflexic bladder with DSD. The other patient required a bladder neck suspension for stress incontinence that was unresponsive to adrenergic treatment.

Of the 15 children with intellectual delay, we have follow up information for nine. Two children had no treatment (one had normal results on videourodynamic studies; one was only 3 years old). The remaining seven all showed improvement with treatment.

An important function of the clinic is to continue to provide the child and parents with encouragement and psychological support. While this may in itself produce improvements in incontinence, it should be noted that before referral such support had been provided by the local hospital and general practice staff. The persistence of symptoms despite this approach locally was the commonest reason for referral, and we feel that the improvement was largely due to specific treatment on the basis of the videourodynamic findings.

\section{Discussion}

The literature concerning lower urinary tract dysfunction in cerebral palsy is limited. ${ }^{16-8}$ McNeal et al found that 18 of 50 patients (36\%) seen in an outpatient clinic over seven months had two or more symptoms of lower urinary tract dysfunction; four were found to have a neuropathic bladder. ${ }^{\prime}$

Decter et al performed urodynamic studies on 57 patients aged 2-20 years who were referred with urological symptoms ${ }^{6} ; 49(86 \%)$ were incontinent. The commonest abnormality was detrusor hyper-reflexia (70\%); three patients showed DSD. Six of the 57 patients $(11 \%)$ had electromyographic evidence of an incomplete lower motor neuron lesion of the distal urethral sphincter. The authors proposed that such a lesion might result from hypoxic injury to the cord,' while a central brain insult would be expected to cause the predominant upper motor neuron type of lesion.

Drigo et al studied 20 children, and urodynamic studies were performed in nine children.? Hyper-reflexia and reduced bladder capacity were found in all, and two had DSD with large urinary residual volumes.

More recently, Mayo described 33 patients, including 10 older than 20 years, who had been referred with lower urinary tract symptoms over a 15 year period. ${ }^{8}$ Difficulty in voiding was the main symptom in 17 patients, including 12 with urgency. True DSD was present in one of these, and eight had hyper-reflexia. The remaining 16 patients complained of urgency and incontinence; 14 of these had hyper-reflexia. Mayo suggests that cerebral palsy patients with difficulty voiding may progress to retention.
The commonest presenting symptom in our series was incontinence, affecting 20 patients (74\%); $56 \%$ had urinary frequency, and $37 \%$ complained of urgency. The impaired mobility of many patients with cerebral palsy means that incontinence is more likely to result when the sudden urge to pass urine develops, as there may be delay in reaching the toilet. Three patients experienced difficulty in initiating voiding, and two had presented in urinary retention, aged 2 weeks and 19 years. Four of our children were considered too severely handicapped to communicate their need for the toilet. This may be an underestimate of the number of children who were unable to communicate their degree of urgency or difficulty in voiding.

Of the 27 patients referred to our clinic, videourodynamic findings were abnormal in 23 (85\%). Hyper-reflexia with reduced capacity was the commonest finding (20); five patients had DSD in addition. These were the main abnormalities found in previous studies. ${ }^{16-8}$ It has been suggested that hyper-reflexia and reduced capacity, manifestations of an upper motor neurone lesion, reflect the cerebral insult leading to cerebral palsy. ${ }^{67}$ However, it should be noted that a high incidence of vesicourethral abnormalities has been found in neurologically normal children with daytime incontinence. Borzyskowski and Mundy reviewed videourodynamic findings in 215 children presenting with persisting daytime incontinence in whom there were no neurological signs. ${ }^{10}$ Detrusor instability (involuntary contractions during bladder filling in neurologically normal subjects) was found in $57 \%$; only $9 \%$ had normal results. Webster et al found detrusor instability in $47 \%$ of 60 children, ${ }^{11}$ also neurologically normal but with voiding dysfunction.

Two patients presented with UTI, and a further 11 had a history of one or more previous UTIs. Vesicoureteric reflux was seen on videourodynamic studies in only one patient. The incidence of VUR in other series of bladder dysfunction in cerebral palsy varies from $1 \cdot 8 \%$ to $35 \% .^{6-8}$ None of these authors comments on renal function or the presence of reflux nephropathy.

Five patients had DSD associated with hyperreflexia and reduced capacity. These children could not be distinguished from those with hyper-reflexia only on the basis of presenting symptoms (table 3). One of these children with VUR, that had been revealed on a previous micturating cystourethrogram but not seen on videourodynamic studies, had bilateral reflux nephropathy and a low glomerular filtration rate. The other four patients, including one with unilateral VUR, had normal upper renal tracts and renal function. The presence of DSD, with resultant obstruction to urinary outflow at the level of the external urethral sphincter, is significant because of its well documented association with renal impairment. ${ }^{41213}$ In previous series of lower urinary tract dysfunction in cerebral palsy, evidence of DSD was found in $\mathbf{1 0}$ of a total of 110 patients..$^{6-8}$ It is evident that DSD is less common in children with cerebral palsy than in those with a truly neuropathic bladder due to an overt spinal cord lesion. In addition, DSD may not have the same significance for 
impaired renal function in cerebral palsy patients. However it should be a cause for concern, and careful assessment of the upper renal tracts and renal function is indicated. Such assessment should be ongoing, as adverse changes due to DSD may progress with time. ${ }^{13}$

Normal results on videourodynamic studies were seen in four of our patients, of whom two had giggle micturition only. The other two patients had daytime incontinence with frequency.

Treatment has led to the improvement or cure of symptoms in 16 of 17 patients who were treated and for whom we have full follow up information, including seven children with intellectual delay as well as motor disorder. Anticholinergic drugs to inhibit hyper-reflexic contractions and improve bladder capacity are effective and well tolerated. Clean intermittent catheterisation was required in five patients with incomplete bladder emptying. This technique has been found to reduce the risk of UTI and upper renal tract dilatation and damage..$^{14-16}$

In conclusion, our review has revealed a high incidence of urodynamic abnormalities in children with cerebral palsy referred with symptoms of lower urinary tract dysfunction. Detrusor hyper-reflexia and reduced capacity were common findings. More serious forms of neuropathic dysfunction and upper urinary tract damage were uncommon. Videourodynamic studies enable treatment to be planned rationally. The mean age at referral of patients was nearly 10 years, but given our findings we feel that children with cerebral palsy and urological symptoms merit early investigations. It should not be assumed that disturbed bladder control is a feature of their condition that has to be accepted. Intellectual delay is not a barrier to successful management. Urinary incontinence in many children with cerebral palsy may be improved or cured.

1 McNeal DM, Hawtrey CE, Wolraich ML, Mapel JR. Symptomatic neurogenic bladder in a cerebral palsied population. Dev Med Child Neurol 1983; 25: 612-6.

2 Whiteside CG. Videocystographic studies with simultaneous pressure and flow recordings. Br Med Bull 1972; $28: 214-9$.

3 Bates CP, Whiteside CG, Turner-Warwick R. Synchronous cine/pressure/flow/cysto-urethrography with special refercine/pressure/flow/cysto-urethrography with special refer-
ence to stress and urge incontinence. Br $\mathcal{F}$ Urol $1970 ; 42$ : ence to

4 Mundy AR, Borzyskowski M, Saxton HM. Videourodynamic evaluation of neuropathic vesicourethral dysfunction in children. BrF Urol 1982; 54: 645-9.

5 Andersen JT, ed. Urodynamics. Terminology and normal values in children, females, and males. Scand $\mathcal{f}$ Urol Nephrol 1988: suppl 114

6 Decter RM, Bauer SB, Khoshbin S, et al. Urodynamic assessment of children with cerebral palsy. $F$ Urol 1987; 138: $1110-2$.

7 Drigo P, Seren F, Artibani W, et al. Neurogenic vesicourethral dysfunction in children with cerebral palsy. Ital $\mathcal{F}$ Neurol Sci 1988; 9: 151-4.

8 Mayo ME. Lower urinary tract dysfunction in cerebral palsy. f Urol 1992; 147: 419-20.

9 Azzarelli B, Roessmann U. Diffuse 'anoxic' myelopathy. Neurology 1977; $27:$ 1049-52

10 Boryzyskowski M, Mundy AR. Videourodynamic assessment of diurnal urinary incontinence. Arch Dis Child 1987; 62: 128-31.

11 Webster GD, Koefoot RB Jr, Sihelnik S. Urodynamic abnormalities in neurologically normal children with micturition dysfunction. F Urol 1984; 132: 74-7.

12 Perkash I. Detrusor-sphincter dyssynergia and detrusor hyperreflexia leading to hydronephrosis during intermittent catheterization. F Urol 1978; 120: 620-3.

13 Sidi AA, Dykstra DD, Gonzalez R. The value of urodynamic testing in the management of neonates with myelodysplasia: testing in the management of neonates with
a prospective study. $\mathcal{F}$ Urol $1986 ; 135: 90-3$.

14 Lapides J, Diokno AC, Lowe BS, Kalish MD. Follow up on unsterile intermittent catheterisation. F Urol 1974; 111: 184-6.

15 Plunkett JM, Braren V. Clean intermittent catheterisation in children. $\mathcal{F}$ Urol 1979; 121: 469-71.

16 Brock WA, So EP, Harbach L, Kaplan GW. Intermittent catheterisation in the management of neurogenic vesicourethral dysfunction in children. F Urol 1981; 125: 391-3. 